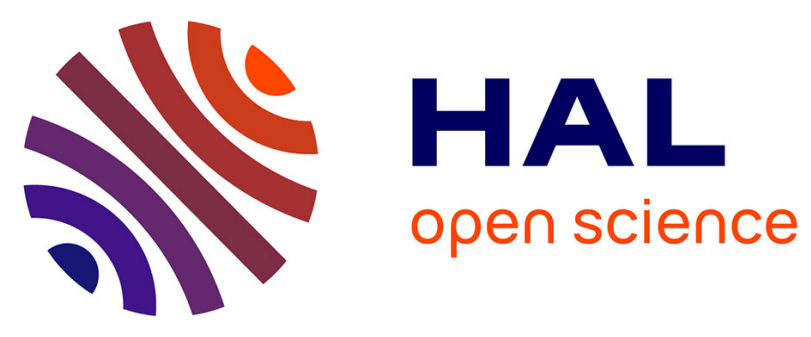

\title{
When synesthesia and savant abilities are mistaken for hallucinations and delusions: contribution of a cognitive approach for their differential diagnosis
}

Lucie Bouvet, Jacques-Edouard Barbier, Nia Cason, Serge Bakchine, Nathalie Ehrlé

\section{To cite this version:}

Lucie Bouvet, Jacques-Edouard Barbier, Nia Cason, Serge Bakchine, Nathalie Ehrlé. When synesthesia and savant abilities are mistaken for hallucinations and delusions: contribution of a cognitive approach for their differential diagnosis. The Clinical neuropsychologist, 2017, 31 (8), pp.1459-1473. 10.1080/13854046.2017.1288269 . hal-01927099

\section{HAL Id: hal-01927099 \\ https://hal.science/hal-01927099}

Submitted on 19 Nov 2018

HAL is a multi-disciplinary open access archive for the deposit and dissemination of scientific research documents, whether they are published or not. The documents may come from teaching and research institutions in France or abroad, or from public or private research centers.
L'archive ouverte pluridisciplinaire HAL, est destinée au dépôt et à la diffusion de documents scientifiques de niveau recherche, publiés ou non, émanant des établissements d'enseignement et de recherche français ou étrangers, des laboratoires publics ou privés. 


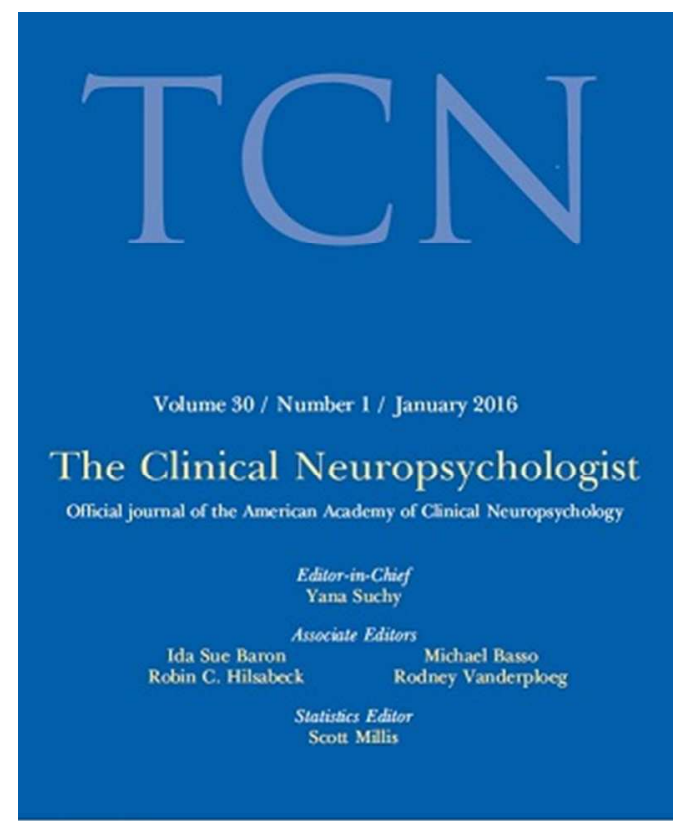

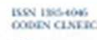

13 Routledge

When synesthesia and savant abilities are mistaken for hallucinations and delusions: contribution of a cognitive approach for their differential diagnosis

\begin{tabular}{|r|l|}
\hline Journal: & The Clinical Neuropsychologist \\
\hline Manuscript ID & TCN-GR 16-201 .R2 \\
\hline Manuscript Type: & Original Article \\
\hline Date Submitted by the Author: & n/a \\
\hline Complete List of Authors: & $\begin{array}{l}\text { Bouvet, Lucie; Universite Toulouse Jean Jaures Centre d'Etudes et de } \\
\text { Recherches en PsychoPathologie } \\
\text { Barbier, Jacques-Edouard; Syndicat national des Psychiatres Privés, } \\
\text { Cason, Nia; Universite de Lille 3, departement of psychology } \\
\text { BAKCHINE, SERGE; Hôpital Maison-Blanche, Service de neurologie } \\
\text { EHRLE, NATHALIE; Reims hospital, Neurology }\end{array}$ \\
\hline Keywords: & \begin{tabular}{l} 
Schizophrenia, synesthesia, savant abilities, differential diagnosis \\
\hline
\end{tabular} \\
\hline
\end{tabular}




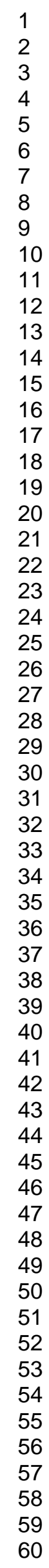

37 
When synesthesia and savant abilities are mistaken for hallucinations and delusions: contribution of a cognitive approach for their differential diagnosis

Short title: Synesthesia, savant syndrome, and schizophrenia

\author{
Lucie Bouvet ${ }^{1}$, Jacques-Edouard Barbier ${ }^{2}, \mathrm{Nia} \mathrm{Cason}^{3}$, Serge Bakchine ${ }^{4}$, Nathalie Ehrlé, \\ ${ }^{1}$ Laboratoire CERPPS (EA7411), Université Toulouse Jean Jaurés, Toulouse, France \\ 2 Syndicat national des Psychiatres Privés, Reims, France \\ ${ }^{3}$ Laboratoire PSITEC (EA 4072), Université de Lille, Lille, France \\ ${ }^{4}$ Service de neurologie, Hôpital Maison-Blanche, Hôpital Universitaire de Reims, Reims, France \\ Corresponding author: \\ Lucie Bouvet \\ Laboratoire CERPPS, \\ University of Toulouse Jean Jaurés \\ 5 Allée Antonio Machado \\ 31000 Toulouse \\ lucie.bouvet@univ-tlse2.fr
}




\begin{abstract}
Objective: Schizophrenia is characterized by hallucinations, delusions, disorganized speech and behavior, and other symptoms that cause social or occupational dysfunction. However, some of these symptoms, such as hallucinations and delusions, can be indicative of other phenomena such as synesthesia and savant abilities. The aim of this paper is to highlight how neurological and psychiatric conditions can be confused and how formal neuropsychological evaluations can be necessary to distinguish them.
\end{abstract}

Method: We report the case of a young woman, VA, who perceived sounds as colors and claimed to have elaborated complex astrophysical reasoning, despite having experienced difficulties at school, especially in mathematics. VA also had difficulties to orient herself, to develop social relationships, and often became confused by daily life situations. These elements were considered as symptoms of schizophrenia

Results: Evaluations revealed that VA exhibited savant abilities in astrophysics and coloredhearing synesthesia. We also found evidence of higher-than-average cognitive functioning. Conclusions: In complex cases, neuropsychological and formal evaluations are necessary to establish a differential diagnosis. Moreover, the case highlights the link between synesthesia and savant abilities.

Keywords: schizophrenia, synesthesia, savant abilities, differential diagnosis 


\section{Introduction}

Neurological and psychiatric symptoms are sometimes difficult to dissociate. Indeed, many neurological diseases cause psychiatric symptoms, and, conversely, some psychiatric illnesses such as schizophrenia and autism involve neuropsychological impairment (Reichenberg, 2010; Wilson et al., 2014). Additionally, some neurological conditions, such as dementia with Lewy bodies or Parkinson's disease, can be confused for psychopathological conditions such as psychosis, especially due to the presence of hallucinations (Weintraub \& Hurtig, 2007). The aim of this paper is to demonstrate how neurological and psychiatric conditions can be sometimes confused, and that neuropsychological and formal evaluations could be important for a differential diagnosis. For this, we report the case of a woman who presented as schizophrenic but whose objective and neuropsychological assessments rather revealed synesthesia and savant abilities.

It is well known that schizophrenia is a psychiatric disorder characterized by hallucinations (hearing voices or seeing things that are not there), delusions (false beliefs, grandiose ideas), negative symptoms (affective and emotional exhaustion), and disorganized speech and motor behavior (APA, 2013). Different forms of schizophrenia have been described (disorganized, catatonic, paranoid, and undifferentiated), and these are diagnoses assigned according to the dominant symptom. In addition to these symptoms, schizophrenia is often accompanied by cognitive deficit (Fioravanti, Carlone, Vitale, Cinti, \& Clare, 2005; Heinrichs \& Zakzanis, 1998; Reichenberg, 2010). According to Reichenberg (2010), the incidence of cognitive deficit in patients with schizophrenia is $55 \%$ to $80 \%$. For instance, a general impairment is observed, with an IQ score below the general population (specifically, the performance IQ score). Executive function and memory are also impaired in this pathology. 
Nonetheless, the diagnosis of schizophrenia can be difficult given that there is no known etiology and no universally accepted test. Hallucinations and delusions are key symptoms of this psychiatric disease, the main criterion being the distortion of reality. For most patients, inappropriate thoughts and distorted perception are easy to diagnose. However, some patients may report unusual perceptions and abilities that, while being exceptional and disconcerting, are not necessarily the same as hallucinations and delusions. We will now discuss how two such exceptional phenomena, synesthesia and savant abilities, may be mistaken for schizophrenia symptoms, hallucinations and delusions.

Synesthesia can be described as a subjective phenomenon where the perception of one particular stimulus automatically elicits an idiosyncratic perception in the same or a different sensory modality. Synesthesia is additive, whereby the triggered perception is added to the sensory perception rather than replacing it (Simner, 2012). More than 60 types of synesthesia have been described (Day, 2014), including time-space synesthesia (e.g., months are associated to specific spatial localizations), grapheme-color synesthesia (e.g., letters are associated to specific colors), and colored-hearing synesthesia (e.g., sounds are associated to specific colors) (Ward, 2013). Because multiple forms of synesthesia exist, it has been difficult to estimate its prevalence among the general population. Some forms are quite rare: grapheme-color and sound-color are estimated to have a prevalence of $0.2 \%$ to $2.8 \%$ in the general population. More frequent forms, such as time-space synesthesia, are estimated to be prevalent in $9 \%$ to $14 \%$ of the general population (Chun \& Hupé, 2013). Synesthesia is thought to be neurological in origin (Hupé \& Dojat, 2015), and is not related to drug use (even if synesthesia can be in certain cases drug induced), or to psychological, psychiatric, or to a specific neurological disease. However, recent studies have reported a higher prevalence of synesthesia in the autistic population (Baron-Cohen et al., 2013; 
Neufeld et al., 2013). We will now consider the potential links between synesthesia and hallucinations, and how these could result in a misdiagnosis.

After noting the crossover between synesthesia and hallucinations, Sagiv et al. (2011) reported the similarities between the two phenomena. Indeed, both are subjective, occur in the absence of an appropriate stimulus, and are not under voluntary control. At first glance, therefore, synesthesia is similar to hallucinations in that both involve the perception of something that is not physically present. However, the main difference between these experiences is the trigger. In synesthesia, the perception is elicited by a stimulus in the same or a different modality, and in hallucinations there is no obvious external trigger. Moreover, the correspondence between the stimulus and the elicited perception is consistent in synesthesia, and the synesthetic experience is thus predictable. This predictability helps a synesthete make sense of their environment. On the contrary, the unpredictability of hallucinations means that they can be disruptive, and those experiencing them can have trouble making sense of their environment. Consequently, the consistency of the association has become the gold standard in evaluating the genuineness of synesthesia (Ward, 2013).

The cognitive profile associated with synesthesia is still unclear, and is made more complicated by the identification of different forms of synesthesia. Synesthesia has been associated with superior cognitive abilities: enhanced mental rotation in time-space synesthesia (Brang, Miller, McQuire, Ramachandran, \& Coulson, 2013), and visual memory for simple abstract pattern in grapheme-color synesthesia (Rothen, Meier, \& Ward, 2012). Using the Intelligence Structure Test, one large-scale survey study found synesthetes to have a superior capacity for reasoning and general knowledge (Rouw \& Scholte, In Press). In exploring the different sub dimensions of intelligence, another large survey adopted the Wechsler Adult 
Intelligence Scale, and showed that synesthetes only possessed superior verbal comprehension compared to the general population (Chun \& Hupé, 2015). Interestingly, there is also preliminary evidence for a diminished performance in some tasks, which may reflect competitions between brain regions in synesthesia (McCarthy \& Caplovitz, 2014). For instance, while grapheme-color synesthetes show enhanced color perception they also display a higher motion-coherence threshold (i.e., an impaired ability to detect coherent motion; Banissy, Tester, et al., 2013) and reduced audio-visual integration (Sinke et al., 2014). This latter result can be related to an impaired motion perception (Safran \& Sanda, 2015). This illustrates how perception can influence cognition, and can lead to superior performance in specific tasks and diminished performance in other tasks. However, as far as we are aware, these are the only studies that have explored this apparent dichotomous performance. After defining synesthesia and its potential link to hallucinations, we will now consider savant abilities and how they can be confused with delusions.

Savant abilities can be defined as exceptional abilities in a specific domain that contrast with the general functioning of a person, often marked by intellectual or developmental disabilities (Bouvet et al., 2014). Many savant abilities can be objectively assessed, as has been reported in music production (Sloboda, Hermelin, \& O’Connor, 1985), drawing (Wallace, Happé, \& Giedd, 2009), and calendrical calculation (Neumann et al., 2010). In some cases, savant abilities can be observed in specialized domain requiring high levels of knowledge and reasoning, such as mathematical and astrophysical reasoning. In these cases, a differential diagnostic between savant abilities and delusion (especially grandiose ideas) may be difficult to carry out without the help of expert. This was true for the case of Jacob Barnett, a young mathematical prodigy, whose own mother could not tell if he was a genius or delusional (Barnett, 2013). Thus, 
for very specialized domains of expertise such as this, the genuineness of savant ability can be difficult to evaluate.

Savant syndrome is quite rare, and only case studies have been published (e.g., Mottron \& Belleville, 1993; Sloboda et al., 1985; Soulières et al., 2010; Young \& Nettelbeck, 1995). Consequently, little is known about the cognitive functioning of savant individuals. Saying this, savant abilities are most often reported in individuals with autism, with an estimated prevalence of $0,5 \%$ of population with autism (Hermelin, 2001). Despite a wide heterogeneity, a specific cognitive profile is observed in those with autism, and is characterized by superior performance in some domains and diminished performance in others. A well-established result is the enhanced performance in tests that require the processing of local elements, such as the block design test of the Wechsler scale and the embedded figures test (Muth, Hönekopp, \& Falter, 2015). Diminished performance is observed in tasks involving theory of mind (Senju, 2012) and executive functioning (Russo et al., 2007). Thus, similarly to synesthesia, savant abilities are commonly accompanied by both enhanced and diminished cognitive abilities.

In summary, it can be difficult to distinguish psychiatric symptoms such as hallucinations and delusions from phenomena such as synesthesia and savant abilities. A differential diagnosis can be further complicated by the fact that synesthesia and savant abilities are more prevalent in some psychiatric conditions. Indeed, autism is associated with a higher prevalence of synesthesia (Baron-Cohen et al., 2013; Neufeld et al., 2013) and savant abilities (Hermelin, 2001). Moreover, a particular personality type has been associated with synesthesia. For instance, synesthetes have been shown to have an increased openness to experience and fantasizing, a decreased agreeableness (Banissy, Holle, et al., 2013; Chun \& Hupé, 2015; Rouw \& Scholte, In Press), and, 
in grapheme-color and colored-hearing synesthesia, schizotypy (positive and disorganized signs) (Banissy et al., 2012).

In the present paper, we present the rare case of VA. VA possesses synesthesia and savant abilities, but was believed to be schizophrenic due to her reports of seeing localized sound in colors, of having developed a complex mathematical reasoning, and talking about the origin of the big bang. These were misinterpreted as hallucinations and delusions. This case report highlights the importance of neuropsychological evaluations in the disentanglement of neurological and psychopathological conditions in complex cases, and illustrates how special abilities can interact.

\section{I- Case history}

\section{Developmental history}

VA, a young woman, was 20 years old at the start of the study. Personal history was provided by VA and was corroborated by her father. VA was born without any difficulties. Intellectual precocity became apparent at an early age. At 16 months old, she started to speak with complete sentences, yet she did not pronounce any single word before this age. During normal development, children are expected to pronounce they first word at around 12 months and to start to master syntax at 3 years old. VA learnt to read at 3 years old and was able to write texts one year later (children usually start to read and write at 5-6 years old). At 3 years old, VA was able to perform mental calculation (children usually acquire this ability at 5-6 years old), and, with a calculator, she understood the concept of decimals and power numbers. She had very specific 
interests - dinosaurs and space - for which she had an encyclopedic knowledge, which is also unusual for a child.

Despite her intellectual precocity, VA experienced motor and coordination difficulties. She started to walk at 24 months old, whereas children are expected to take their first steps at around 12 months old. She fell quite regularly and was unable to roller skate or to swim later in childhood. She still has difficulties to orient herself and can become confused about everyday life situations. For example, VA explained that when she drops a pack of pasta on the floor, she is unable to work out how to pick it up. She also has issues with social relationships. At school, she was socially excluded, often a target of bullying, and had few friends.

VA experienced global difficulties throughout her studies. When she started school, it was noticed that she found it difficult to understand ambiguous instructions. She performed quite well during primary school; while she had clear difficulties in mathematics, she performed quite well in biology. After high school, she enrolled in a course in astronomy that she gave up due to her difficulties with mathematics. She then enrolled at a university institute of technology, where she ranked as the lowest performing student on her course. Throughout her scholarship, VA had specific difficulties in mathematics and in formal comprehension.

VA also has a familial history of psychiatric disorders: her half-sister and half-brother suffer from eating disorders (bulimia), her father suffers from paranoid personality disorder, and her mother was described as being psychologically and physically violent towards her daughters and her husband.

\section{Psychiatric diagnosis}

Two years prior, VA was referred to a psychiatrist who diagnosed social phobia and schizophrenia. These conclusions were based on severe disturbances of social behavior (mainly 
fear and avoidance of social groups) and on a misinterpretation of what VA reported as 'special competences'. VA claimed that she had the special ability to see forms and colors when hearing sounds, and even images 'turning around her or going through her', especially when listening music. She also claimed that she was working on a theory of the 'big bang'. She explained she was trying to develop a mathematical reasoning based on visual representations from 2 to 6 spatial dimensions in order to describe black holes, white holes, and worm holes. The psychiatrist considered VA to be experiencing multimodal hallucinations and delusions of scientific aptitudes. Combined with her family history of psychiatric disorders, this logically led to the diagnosis of schizophrenic disorder.

\section{II- Neuropsychological evaluation}

VA came to the neurological department for vocational guidance. We first conducted a neuropsychological assessment. The main objective of this assessment was to evaluate the general functioning of VA by exploring general intelligence, memory, executive functioning, and visuo-spatial abilities. The second objective was to evaluate if VA exhibited a deficit in executive function and working memory, as has been found in schizophrenia (Reichenberg, 2010).

\section{General intelligence}

An assessment of intelligence was made using the Wechsler Adult Intelligence Scale III (WAIS III ; Wechsler, 2000). The results of this evaluation indicated a superior verbal quotient compared to the general population (see Table 1). Although VA showed high abilities in verbal, perceptual, and working memory domains, her index of speed processing was within the normal range. The difference between VA's verbal/perceptual intelligence and her speed processing 
could be suggestive of difficulties to rapidly process information. Despite her reported difficulties in math, no difficulty in the arithmetic subtest was observed. However, her reasoning was sometimes unusual. For example, for the problem 'A person buys the third of a building plot and another person a quarter of the same plot. Which proportion remains to buy?', VA answered very quickly ' $42 \%$ '; she explained that she counted the cubes within a 3D structure but was unable to convert her mathematical reasoning into fractions to give the expected response ' $5 / 12$ '.

\begin{abstract}
Memory
Specific evaluation of memory was also carried out using the Wechsler Memory Scale III (WMS - III ; Wechsler, 2001). This evaluation highlighted VA's superior memory abilities for auditory information as well as a high working memory capacity (see Table 1).
\end{abstract}

[Table 1]

\title{
Executive functions
}

Executive functioning was also assessed with normed tests. The first part of the Trail Making Test (TMT; Tombaugh, 2004) involves connecting numbers in ascending order, and in the second part involves linking letters and numbers in alternation in an ascending order. In the Wisconsin Card-Sorting Test (WCST ; Heaton, Chelune, Talley, Kay, \& Curtis, 2007), cards must be sorted as a function of one criterion, which then switches. The verbal fluency test evaluates the capacity to generate words with a phonetic or semantic link within two minutes (Cardebat, Doyon, Puel, Goulet, \& Joanette, 1990). VA's results revealed no particular difficulty regarding capacity of mental flexibility and fluency. The TMT indicated slow reaction times, which corroborated VA's specific difficulty to rapidly process information (see Table 2). 


\section{Visuo-spatial abilities}

Visuo-spatial abilities were also investigated (Table 2) using normed tests. The Hooper visual organization test measures the capacity to recognize a shape from puzzled elements (Hooper, 1983). In the 15 objects test, the task is to denominate as many perceived objects as possible in a figure composed of 15 objects (Pillon et al., 1989). In the bell's test, 35 bells among 280 distractors must be detected (Gauthier, Deahault, \& Joanette, 1989). The Rey complex figure involves reproducing a drawing of a complex figure by copy and then by memory (Rey, 1959). Regarding VA's performance, some difficulties were noticed in the bell's test and in the copy task of the Rey complex figure test. These results suggest a specific difficulty in the visual domain.

\section{[Table 2]}

\section{Mathematical abilities}

To evaluate VA's difficulty in formal calculation, she was asked to solve written mathematical problems with the application of a formula (simple operations, calculation of power number, fractional number, and Thales and Pythagorean Theorem). This evaluation revealed her difficulty to master formal calculation. It appears that while VA was able to easily perform mental operations, writing these operations down was a challenge. In addition, VA showed difficulties to generalize formulas and to understand code correspondence between letters and numbers.

To summarize, the neuropsychological profile of VA indicates cognitive abilities in the superior norm. A very efficient working memory was also observed, as well as intact executive functions. The auditory modality was particularly efficient, but to the detriment of the visual modality, as 
evident by difficulties in visuo-spatial abilities (copy task of the Rey Figure test, Embedded Figure Test, Bell's test). Difficulties to rapidly process information and to master formal calculation were also found.

This cognitive profile is not consistent with the one typically observed in schizophrenia, which is characterized by a deficit in executive function and working memory (Reichenberg, 2010). Given this, we performed a psychometric exploration of her auditory visual perception in order to evaluate whether VA's profile could be related to the phenomenon of synesthesia. Moreover, we sought an expert's opinion to assess the veracity of her astrophysical reasoning abilities.

\section{III - Psychometric evaluation of synesthesia}

Description. VA reported possessing this particular association for as long as she could remember. She perceives colors for any acoustic stimuli (verbal and non verbal). Colors vary according to timbre, loudness, and frequency. Moreover, these colors are organized in a dynamic form. For verbal sounds, each phoneme is associated to a specific color, and thus, on hearing a word, VA perceives a succession of colors. In turn, for words or sentences, the color is rapidly replaced by a visual dynamic image that represents the word or the sentence. She reported that this image has often caused her to lose the thread of a conversation. For nonverbal sounds, colors are more intense and are localized all around her $\left(360^{\circ}\right)$. High-pitched sounds are localized at the top of her visual field and low-pitched sounds at the bottom. She also reported that she feels the spectrogram of a sound and that certain frequencies can 'pierce' her. She compared this to the unpleasant sensation experienced on hearing the noise of a piece of chalk on a blackboard. VA explained that her sound-color associations had helped her to learn foreign languages; she is a 
bilingual French-English speaker and fluent in German, which she described as easy to learn. To conclude, the description of VA's auditory-visual perception is very detailed and each perception seems to be elicited by a specific trigger, which fits more with the definition of synesthesia than hallucination. Because one key feature of synesthesia is the predictability/consistency of the perception, a psychometric evaluation of the consistency of her auditory-visual associations was made.

Evaluation of the consistency of VA's perceptions. To evaluate the stability of VA's perception, we first tested her associations between phonemes and colors. Thirty-seven phonemes present in French were orally presented once at the time of assessment and again 2 months later (see Figure 1). Each phoneme was presented twice in order to avoid confusion: one alone and once in the context of a word. VA was then asked with the software Paint $(\mathrm{C}$ to create the color associated to the phoneme by adjusting 3 parameters (hue, saturation, and luminosity). A color is a combination of red, green, and blue (when all these values are set at 0 , the color is white and when they are all 255, the color is black). The hue matches the $\mathrm{x}$-axis of the rainbow while saturation matches the y-axes. The luminosity (lightness/darkness) ranges from 0 to 240 . VA's results were consistent across the two sessions. VA reported that there was more sunshine on the retest session, and so the colors reported were a little brighter than those of the first session. For some sounds, she reported two colors.

We then tested the stability of VA's sound-color associations for non-verbal sounds. The consistency of these associations was tested using the online Synesthesia Battery (Eagleman, Kagan, Nelson, Sagaram, \& Sarma, 2007). VA performed the Piano Scale Color Picker Test and the Instrument Color Picker Test. In the first test, 13 pitches (from C4 to C5, piano timbre) are played at least three times in a random order. In the second test, one identical tone is played by 18 
instruments (guitar, trombone, violin, cymbal, etc.) in a random order. In both tests, participants must choose a corresponding color after hearing each sound, from a palette of $256 \times 256 \times 256$ colors. These tests evaluate the consistency of responses across trials by calculating the color variation between different trials. VA obtained a score under 0.5 (a non-synesthetic person scores above 2, which indicates a variation between the chosen colors across trials). This score indicated that she was consistent across the reported colors, which is specific to synesthesia.

[Figure 1]

To summarize, VA clearly showed consistent color associations between verbal and non-verbal sounds and colors. Considering that the gold standard of synesthesia is the consistency of associations, this indicates that VA possesses colored-hearing synesthesia.

\section{IV-Astrophysical reasoning}

Description. VA reported a deep interest in astronomy and claimed to have the ability to calculate ephemeris (i.e., sunsets and the rising of stars) using a method that she had developed when she was 16 years old. VA also claimed that she elaborated astrophysical theory using graphical reasoning. Her thinking was that black holes could create a big bang, in the sense that white holes are the opposite of black holes. She also theorized that the gravitation of black holes could have an impact on the formation of galaxies. She reported that her ability to form a mental image of infinity helped her to develop this reasoning and to understand that the positive and 
negative infinites are one. As we were unable to dissociate delusions from genuine abilities in astrophysics, an expert was asked to test the veracity of VA's reasoning.

Evaluation of the veracity of $V A$ 's reasoning by an expert. Marc Lachièze-Rey, astrophysicist and researcher, and head of a French CNRS laboratory at that time (Astroparticule et Cosmologie, UMR 7164, Paris 7 University), agreed to meet VA and to evaluate her theories. After a two-hour meeting, Prof. Lachièze-Rey confirmed that VA's theory about the big bang was scientifically correct and original. He also reported that some other researchers had proposed an alternative method to calculate ephemeris based on calculation and not on visuo-spatial reasoning, and that their method was more time consuming that VA's. Prof. Lachièze-Rey also confirmed that VA possessed exceptional geometric abilities, but that her difficulties to turn them into formal calculation make it hard to share with the scientific community.

In sum, the evaluation of VA's reasoning by an expert revealed the presence of savant abilities in the field of astrophysics.

\section{V- Links between cognition, synesthesia, and savant abilities}

Given VA's atypical cognitive profile, her auditory-visual synesthesia, and her savant abilities for astrophysical reasoning, we can wonder to what extent they might be linked or be part of the same phenomenon. In VA's case, it seems that her ability to form a visual representation might be involved in the development of her savant abilities. Indeed, in addition to her colored-hearing synesthesia, her advanced ability for visual representations apply to quantity value, whereby she automatically visualizes a quantity when hearing or reading about it: little dots for small quantities and a string of squares for larger quantities. Her representation of quantity helps her to 
calculate power numbers. For squared numbers, she creates a two dimensional representation and counts each square of the representation. The volume can grow or shrink according to the number value and is modified according to the calculation being performed. For instance, she adds another dimension (3D) for cube numbers. For higher power numbers, she adds even more dimensions to her visual representation. Beyond power 6 - a representation with 6 spatial dimensions - VA found this uncomfortable. Even though VA knew that these multi-dimensional representations cannot be real, she described them to be as vivid as $2 \mathrm{D}$ and $3 \mathrm{D}$ representations. VA reported that this ability to form a mental image of not only a number, but also infinity, helped her to develop her astrophysical reasoning. This further exemplifies the potential link between her savant abilities and synesthesia. Interestingly, this capacity might also explain her difficulty to master formal calculation, whereby her inability to understand mathematical formula may be a result of her difficulty to visualize them.

\section{Discussion}

The aim of this paper was to present the case of an individual described as suffering from schizophrenia, but for whom neuropsychological and formal evaluations revealed synesthesia and savant abilities. We will now discuss elements of the differential diagnosis and the link between synesthesia and savant abilities.

Some elements of VA's personal history are congruent with the diagnosis of schizophrenia, including social withdrawal and difficulties at school. Moreover, the multiple cases of mental illness observed in her family may have also biased the diagnosis of schizophrenia. Given this context, it is understandable why VA's reports concerning her ability to 
perceive sound in color and to perform high astrophysical reasoning were interpreted as auditory hallucinations and delusions. However, VA exhibited a superior cognitive profile and exceptional memory for auditory information with no deficit in executive functions. The only difficulty observed was the processing of visuo-spatial information. Thus, this cognitive profile is not consistent with the one typically observed in schizophrenia, characterized by a deficit in executive function and working memory (Reichenberg, 2010). Furthermore, the genuineness of her synesthesia and astrophysical reasoning also discredits this diagnosis of schizophrenia. Indeed, without these elements, the only symptom in favor of a diagnosis of schizophrenia is social withdrawal; this alone is not specific enough for a diagnosis and can be observed in other psychiatric pathologies (such as autism), in specific neuronal lesions, or even in the general population (preference for solitude).

The investigation of VA's auditory associations revealed her hearing-color synesthesia to be authentic. However, her synesthetic associations are atypical. Indeed, the description made by VA indicates that her synesthesia is disruptive. Generally, the synesthetic triggered sensation does not replace the original perception but it is added to it (Ward, 2013). In the case of VA, the triggered perception replaces the original perception in memory. This means that she can be overwhelmed by her synesthesia and often unable to keep track of a conversation. This is quite atypical for synesthesia and, furthermore, is a factor used to dissociate between hallucinations and synesthesia. This raises the question as to what extent hallucinations and synesthesia may be part of the same continuum, and whether these phenomena may rely on the same mechanisms. This idea has already been mentioned in the literature (Pearson \& Westbrook, 2015; Sagiv, Ilbeigi, \& Ben-Tal, 2011), but there is no research that further illustrates the distinctions between synesthesia and hallucinations. At the cognitive level, synesthesia is characterized by superior 
performance in some tasks (such as mental rotation or visual memory in certain forms of synesthesia) as well as diminished performance in other tasks (such as higher motion-coherence threshold or audio-visual integration in some forms of synesthesia). While the present results highlight a cognitive profile for synesthesia that is characterized by peaks and troughs in cognitive functioning, further research is needed to better determinate a specific cognitive profile in synesthesia.

Can VA's astrophysical reasoning be considered a savant ability? Savant abilities contrast with the general functioning of the individual in terms of developmental and/or intellectual abilities (Bouvet et al., 2014). In the case of VA, her reasoning capacity contrasts with her difficulties to master formal calculation, which points to the presence of savant abilities. Her savant abilities are also quite atypical from those reported in the literature (e.g., music, drawing, memory). In the literature, there are few reports of co-occurring synesthesia and savant syndrome (Bor, Billington, \& Baron-Cohen, 2007; Bouvet et al., 2014) and few authors have explored the potential link between them. Simner et al. (2009) proposed that synesthesia might be a foundation of savantism. In this study, the authors observed that individuals with visuo-spatial synesthesia exhibited superior abilities in visuo-spatial tasks. In the case of VA, her capacity to visualize quantity forms the basis of her power number calculation and astrophysical reasoning. Moreover, the rapid forgetting of the verbal code, once this is converted into a visual format, might play a role in VA's difficulties to understand formulas, theorems, and the symbolic status of letters in formulas. It can be hypothesized that her 'overwhelming' synesthesia might be caused by an exceptional mental imagery. Indeed, studies have found that synesthetes possess superior mental imagery (Chun \& Hupé, 2015) and some authors related synesthesia to the phenomenon of 'phantom perception' involved in mental imagery (Pearson \& Westbrook, 2015). We propose 
that this vivid and atypical imagery helped VA to develop an atypical form of savant ability, that is, abstract astrophysical reasoning. This ability might also be involved in her difficulty in the social domain. Indeed, VA's synesthesia meant that she often lost the thread of conversations, and her multi-dimensional representations are difficult for other people to visualize. This raises the question as to what extent synesthesia and savant abilities impact at the social level despite the absence of pathological disease in persons with no pathological disease. As of yet, no studies have directly addressed this question in the field of synesthesia.

[Table 3]

To conclude, this clinical case illustrates how neuropsychological investigation may be required for complex behavioral diagnosis. The neuropsychological evaluation allowed us to evaluate if VA's cognitive profile was in line with the one typically observed in schizophrenia, and to formally evaluate the non-psychiatric origin of her specific abilities (see Table 3). In addition, the systematic and the complete evaluation of patients helps us to understand how the same phenomenon can lead to superior abilities and simultaneously diminished performance. In the case of VA, we believe that her vivid mental imagery is related to her overwhelming synesthesia and atypical savant abilities. Moreover, we believe that VA's difficulty with visuospatial tasks and formal calculation are also a result of vivid mental imagery. This kind of dichotomous performance is poorly described in the literature. The study of complex cases like VA highlight the fact that systematic evaluations of difficulties should be made and, more generally, uncover the links between perception and cognition.

\section{Acknowledgments}


We are greatly indebted to VA, who consented to her data being used for research and publication. We also thank Jean-Michel Hupé and an anonymous reviewer for their helpful comments on the manuscript.

\section{References}

APA. (2013). Diagnostic and statistical manual of mental disorders (5th ed.). Arlington, VA: American Psychiatric Publishin.

Banissy, M. J., Cassell, J. E., Fitzpatrick, S., Ward, J., Walsh, V. X., \& Muggleton, N. G. (2012). Increased positive and disorganised schizotypy in synaesthetes who experience colour from letters and tones. Cortex, 48(8), 1085-1087. https://doi.org/10.1016/j.cortex.2011.06.009

Banissy, M. J., Holle, H., Cassell, J., Annett, L., Tsakanikos, E., Walsh, V., ... Ward, J. (2013). Personality traits in people with synaesthesia: Do synaesthetes have an atypical personality profile? Personality and Individual Differences, 54(7), 828-831. https://doi.org/10.1016/j.paid.2012.12.018

Banissy, M. J., Tester, V., Muggleton, N. G., Janik, A. B., Davenport, A., Franklin, A., ... Ward, J. (2013). Synesthesia for Color Is Linked to Improved Color Perception but Reduced Motion Perception. Psychological Science, 24(12), 2390-2397. https://doi.org/10.1177/0956797613492424

Barnett, K. (2013). The Spark: A Mother's Story Of Nurturing, Genius, and autism. Random House of Canada.

Baron-Cohen, S., Johnson, D., Asher, J., Wheelwright, S., Fisher, S., Gregersen, P., \& Allison, C. (2013). Is synaesthesia more common in autism? Molecular Autism, 4(1), 1-6.

https://doi.org/10.1186/2040-2392-4-40 
Bor, D., Billington, J., \& Baron-Cohen, S. (2007). Savant memory for digits in a case of synaesthesia and Asperger syndrome is related to hyperactivity in the lateral prefrontal cortex. Neurocase, 13(5), 311-9. https://doi.org/10.1080/13554790701844945

Bouvet, L., Donnadieu, S., Valdois, S., Caron, C., Dawson, M., \& Mottron, L. (2014). Veridical mapping in savant abilities, absolute pitch, and synesthesia: An autism case study. Frontiers in Psychology, 5. https://doi.org/10.3389/fpsyg.2014.00106

Brang, D., Miller, L., McQuire, M., Ramachandran, V. S., \& Coulson, S. (2013). Enhanced mental rotation ability in time-space synesthesia. Cognitive Processing. https://doi.org/10.1007/s10339-0130561-5

Cardebat, D., Doyon, B., Puel, M., Goulet, P., \& Joanette, Y. (1990). Formal and semantic lexical evocation in normal subjects. Performance and dynamics of production as a function of sex, age and educational level. Acta neurologica Belgica, 90(4), 207-17.

Chun, C., \& Hupé, J.-M. (2013). Mirror-touch and ticker tape experiences in synesthesia. Frontiers in Psychology, 4. https://doi.org/10.3389/fpsyg.2013.00776

Chun, C., \& Hupé, J.-M. (2015). Are synesthetes exceptional beyond their synesthetic associations? A systematic comparison of creativity, personality, cognition, and mental imagery in synesthetes and controls. British Journal of Psychology. https://doi.org/10.1111/bjop.12146

Eagleman, D., Kagan, A., Nelson, S., Sagaram, D., \& Sarma, A. (2007). A standardized test battery for the study of Synesthesia. Journal of Neuroscience Methods, 159(1), 139-145.

Fioravanti, M., Carlone, O., Vitale, B., Cinti, M. E., \& Clare, L. (2005). A Meta-Analysis of Cognitive Deficits in Adults with a Diagnosis of Schizophrenia. Neuropsychology Review, 15(2), 73-95. https://doi.org/10.1007/s11065-005-6254-9

Gauthier, L., Deahault, F., \& Joanette, Y. (1989). The Bells Test: A quantitative and qualitative test for visual neglect. International Journal of Clinical Neuropsychology, 11(2), 49-54. 
Heaton, R., Chelune, G., Talley, J., Kay, G., \& Curtis, G. (2007). WCST: Test de classement de cartes du Wisconsin. Hogrefe Editions.

Heinrichs, R. W., \& Zakzanis, K. (1998). Neurocognitive deficit in schizophrenia: A quantitative review of the evidence. Neuropsychology, 12(3), 426-445. https://doi.org/10.1037/0894-4105.12.3.426

Hermelin, B. (2001). Bright Splinters of the Mind: A Personal Story of Research with Autistic Savants. London: Jessica Kingsley Publishers.

Hooper, H. E. (1983). The Hooper Visual Organization Test manual. Los Angeles, CA: Western Psychological services.

Hupé, J.-M., \& Dojat, M. (2015). A critical review of the neuroimaging literature on synesthesia. Frontiers in Human Neuroscience, 9, 103. https://doi.org/10.3389/fnhum.2015.00103

McCarthy, J. D., \& Caplovitz, G. P. (2014). Color synesthesia improves color but impairs motion perception. Trends in Cognitive Sciences, 18(5), 224-226. https://doi.org/10.1016/j.tics.2014.02.002

Mottron, L., \& Belleville, S. (1993). A study of perceptual analysis in a high-level autistic subject with exceptional graphic abilities. Brain \& Cognition, 23(2), 279-309.

Muth, A., Hönekopp, J., \& Falter, C. M. (2015). Visuo-Spatial Performance in Autism: A Meta-analysis. Journal of Autism and Developmental Disorders, 44(12), 3245-3263. https://doi.org/10.1007/s10803-014-2188-5

Neufeld, J., Roy, M., Zapf, A., Sinke, C., Emrich, H. M., Prox-Vagedes, V., ... Zedler, M. (2013). Is synaesthesia more common in patients with Asperger syndrome? Frontiers in Human Neuroscience, 7. https://doi.org/10.3389/fnhum.2013.00847

Neumann, N., Dubischar-Krivec, A. M., Braun, C., Löw, A., Poustka, F., Bölte, S., \& Birbaumer, N. (2010). The mind of the mnemonists: an MEG and neuropsychological study of autistic memory savants. Behavioural brain research, 215(1), 114-21. https://doi.org/10.1016/j.bbr.2010.07.008 
Pearson, J., \& Westbrook, F. (2015). Phantom perception: voluntary and involuntary nonretinal vision. Trends in Cognitive Sciences, 19(5), 278-284. https://doi.org/10.1016/j.tics.2015.03.004

Pillon, B., Dubois, B., Bonnet, A. M., Esteguy, M., Guimaraes, J., Vigouret, J. M., ... Agid, Y. (1989). Cognitive slowing in Parkinson's disease fails to respond to levodopa treatment: the 15-objects test. Neurology, 39(6), 762-768.

Reichenberg, A. (2010). The assessment of neuropsychological functioning in schizophrenia. Dialogues in Clinical Neuroscience, 12(3), 383-392.

Rey, A. (1959). Validity of the Trail Making test as an indicator of organic brain damage. Paris: ECPA. Rothen, N., Meier, B., \& Ward, J. (2012). Enhanced memory ability: Insights from synaesthesia. Neuroscience \& Biobehavioral Reviews, 36(8), 1952-1963. https://doi.org/10.1016/j.neubiorev.2012.05.004

Rouw, R., \& Scholte, H. S. (In Press). Personality and cognitive profiles of a general synesthetic trait. Neuropsychologia. https://doi.org/10.1016/j.neuropsychologia.2016.01.006

Russo, N., Flanagan, T., larocci, G., Berringer, D., Zelazo, P. D., \& Burack, J. A. (2007). Deconstructing executive deficits among persons with autism: implications for cognitive neuroscience. Brain and Cognition, 65(1), 77-86. https://doi.org/10.1016/j.bandc.2006.04.007

Safran, A. B., \& Sanda, N. (2015). Color synesthesia. Insight into perception, emotion, and consciousness. Current Opinion in Neurology, 28(1), 36-44. https://doi.org/10.1097/WC0.0000000000000169

Sagiv, N., Ilbeigi, A., \& Ben-Tal, O. (2011). Reflections on synaesthesia, perception, and cognition. Intellectica, 55, 81-94.

Senju, A. (2012). Spontaneous theory of mind and its absence in autism spectrum disorders. The Neuroscientist: A Review Journal Bringing Neurobiology, Neurology and Psychiatry, 18(2), 108-113. https://doi.org/10.1177/1073858410397208 
Simner, J. (2012). Defining synaesthesia. British Journal of Psychology, 103(1), 1-15. https://doi.org/10.1348/000712610x528305

Simner, J., Mayo, N., \& Spiller, M. (2009). A foundation for savantism? Visuo-spatial synaesthetes present with cognitive benefits. Cortex, 45(10), 1246-60. https://doi.org/10.1016/j.cortex.2009.07.007

Sinke, C., Neufeld, J., Zedler, M., Emrich, H. M., Bleich, S., Münte, T. F., \& Szycik, G. R. (2014). Reduced audiovisual integration in synesthesia - evidence from bimodal speech perception. Journal of Neuropsychology, 8(1), 94-106. https://doi.org/10.1111/jnp.12006

Sloboda, J. A., Hermelin, B., \& O'Connor, N. (1985). An exceptional musical memory. Music Perception, 3(2), 155-169.

Soulières, I., Hubert, B., Rouleau, N., Gagnon, L., Tremblay, P., Seron, X., \& Mottron, L. (2010). Superior estimation abilities in two autistic spectrum children. Cognitive Neuropsychology, 27(3), 261-76. https://doi.org/10.1080/02643294.2010.519228

Tombaugh, T. N. (2004). Trail Making Test A and B: Normative data stratified by age and education. Archives of Clinical Neuropsychology, 19(2), 203-214. https://doi.org/10.1016/S08876177(03)00039-8

Wallace, G., Happé, F., \& Giedd, J. (2009). A case study of a multiply talented savant with an autism spectrum disorder: neuropsychological functioning and brain morphometry. Philosophical transactions of the Royal Society of London. Series B, Biological sciences, 364(1522), 1425-32. https://doi.org/10.1098/rstb.2008.0330

Ward, J. (2013). Synesthesia. Annual review of psychology, 64(1), 49-75. https://doi.org/10.1146/annurev-psych-113011-143840 Wechsler, D. (2000). WAIS III. Echelle d'intelligence de Wechsler pour adultes. Troisième édition. ECPA. Wechsler, D. (2001). MEM-III. Echelle Clinique de mémoire. Troisième édition. ECPA. 
Weintraub, D., \& Hurtig, H. I. (2007). Presentation and Management of Psychosis in Parkinson's Disease and Dementia With Lewy Bodies. American Journal of Psychiatry, 164(10), 1491-1498. https://doi.org/10.1176/appi.ajp.2007.07040715

Wilson, C. E., Happé, F., Wheelwright, S. J., Ecker, C., Lombardo, M. V., Johnston, P., ... Murphy, D. G. M. (2014). The neuropsychology of male adults with high-functioning autism or asperger syndrome. Autism Research: Official Journal of the International Society for Autism Research, 7(5), 568-581. https://doi.org/10.1002/aur.1394

Young, R. L., \& Nettelbeck, T. (1995). The abilities of a musical savant and his family. Journal of Autism and Developmental Disorders, 25(3), 231-48. 
Table 1. VA's intellectual efficiency and memory

\begin{tabular}{|c|c|c|c|c|c|}
\hline \multirow[b]{2}{*}{ Tests } & \multicolumn{2}{|c|}{ Standard } & \multirow[b]{2}{*}{ Tests } & \multicolumn{2}{|l|}{ Standar } \\
\hline & $\begin{array}{l}\text { / Scale } \\
\text { score }\end{array}$ & Percentile & & $\begin{array}{l}d / \text { Scale } \\
\text { score }\end{array}$ & Percentile \\
\hline WAIS-III & & & WAIS-III & & \\
\hline Verbal IQ & 132 & 98 & Performance IQ & 115 & 84 \\
\hline Verbal comprehension index & 125 & 95 & Perceptual organization & 126 & 96 \\
\hline Similarities & 13 & 84 & index & & \\
\hline Vocabulary & 15 & 95 & Picture completion & 16 & 98 \\
\hline Information & 15 & 95 & Block design & 13 & 84 \\
\hline (Comprehension) & 15 & 95 & Matrix reasoning & 13 & 84 \\
\hline & & & (Picture arrangement) & 10 & 50 \\
\hline & & & (Objet assembly) & 12 & 75 \\
\hline Working memory index & 130 & 98 & & & \\
\hline Digit Span & 17 & 99 & Processing speed index & 97 & 42 \\
\hline Arithmetic & 14 & 91 & Digit symbol-coding & 9 & 37 \\
\hline Letter number sequencing & 14 & 91 & Symbol search & 10 & 50 \\
\hline WMS III & & & WMS III & & \\
\hline Immediate memory index & 126 & 96 & General delayed & 99 & 47 \\
\hline Auditory immediate memory & 140 & $>99$ & memory index & & \\
\hline index & & & Auditory delayed index & 110 & 75 \\
\hline Visual immediate memory & 106 & 66 & Visual delayed index & 97 & 42 \\
\hline index & & & Auditory recognition & 91 & 17 \\
\hline Working memory index & 123 & 94 & delayed index & & \\
\hline
\end{tabular}


Notes : WAIS III: Wechsler Adult Intelligence Scale (french version ; Weschsler, 2000) ; WMS III : Wechsler Memory Scale (french version; Wechsler, 2001). 
Table 2. VA's executive and visuo-spatial functions

\begin{tabular}{|c|c|c|}
\hline Tests & Score & Score according to norms \\
\hline \multicolumn{3}{|l|}{ Executive functions } \\
\hline \multicolumn{3}{|l|}{ Trail making test } \\
\hline$A$ & $23 s$ & 40th percentile \\
\hline$B$ & $49 s$ & 40th percentile \\
\hline \multicolumn{3}{|l|}{ Wisconsin Card Sorting Test } \\
\hline Number of categories achieved & 6 & $>16$ percentile \\
\hline Total errors & 8 & 96th percentile \\
\hline Perseverative errors & 4 & 96th percentile \\
\hline \multicolumn{3}{|l|}{ Verbal fluency } \\
\hline Phonetic (R) & 14 words & $-0.6 S D$ \\
\hline Semantic (fruits) & 22 words & $+0.7 S D$ \\
\hline \multicolumn{3}{|l|}{ Visuo-spatial domain } \\
\hline Hooper visual organization test & $25 / 30$ & T score: $41-55$ \\
\hline 15 objects test & $12 / 15$ & $N A$ \\
\hline \multicolumn{3}{|l|}{ Bell's Test } \\
\hline Number of correct answers & $34 / 35$ & $N A$ \\
\hline Number of auto corrections & 5 & $-2.5 S D$ \\
\hline \multicolumn{3}{|l|}{ Rey Complex Figure } \\
\hline Copy & $31 / 36$ & $-2.7 S D$ \\
\hline Immediate recall & $23.5 / 36$ & $0.5 S D$ \\
\hline Delayed recall & $18 / 36$ & $0.7 S D$ \\
\hline Recognition & $22 / 24$ & $N A$ \\
\hline
\end{tabular}

URL: http://mc.manuscriptcentral.com/ntcn 
1

2

3

4

5

6

7

8

9

10

11

12

13

14

15

16

17

18

19

20

21

22

23

24

25

26

27

28

29

30

31

32

33

34

35

36

37

38

39

40

41

42

43

44

45

46

47

48

49

50

51

52

53

54

55

56

57

58

59

60

Notes : Trail making Test : canadian norms (Tombaugh, 2004); Wisconsin Cord Sorting Test : french norms

(Heaton et al., 2007) ; Verbal fluency : french norms (Cardebat et al., 2000); Hooper visual organization test :

US norms (Hooper, 1983) ; 15 objects test : french norms (Pillon et al., 1989) ; Bell’s test : french norms

(Gauthier et al., 1989) ; Rey Complex Figure : french norms ( Rey, 1960). 
Table 3. Different manifestations observed in schizophrenia, synesthesia, and savant abilities

\section{$\begin{array}{lll}\text { Schizophrenia Synesthesia Savant abilities } & \text { Sy }\end{array}$}

\begin{tabular}{|c|c|c|c|}
\hline Extraordinary ability & $\begin{array}{l}\text { Belief in extraordinary } \\
\text { abilities that are not } \\
\text { real }\end{array}$ & None & $\begin{array}{l}\text { Genuine superior ability in one } \\
\text { specific domain (art, memory, } \\
\text { mathematics) }\end{array}$ \\
\hline $\begin{array}{l}\text { Unusual } \\
\text { perception }\end{array}$ & $\begin{array}{l}\text { Perception of } \\
\text { something that is not } \\
\text { there, with no obvious } \\
\text { trigger. The } \\
\text { perception is not } \\
\text { automatic and can be } \\
\text { different each time. }\end{array}$ & $\begin{array}{l}\text { Perception of something } \\
\text { that is not there resulting } \\
\text { from one particular trigger } \\
\text { stimulus that is physically } \\
\text { present: the perception is } \\
\text { automatically elicited and } \\
\text { similar each time. }\end{array}$ & None \\
\hline $\begin{array}{c}\text { Atypical social } \\
\text { personality }\end{array}$ & $\begin{array}{l}\text { - Emotional } \\
\text { exhaustion } \\
\text { - Social withdrawal }\end{array}$ & $\begin{array}{l}\text { - Signs of positive schizotypy } \\
\text { - Increased openness to } \\
\text { experiences } \\
\text { - Decreased agreeableness }\end{array}$ & $\begin{array}{l}\text { When reported in co- } \\
\text { occurrence with autism: } \\
\text { - social withdrawal }\end{array}$ \\
\hline Cognitive profile & $\begin{array}{l}\text { - Deficit in executive } \\
\text { functions } \\
\text { - Deficit in working } \\
\text { memory } \\
\text { - Difficulties of } \\
\text { attention }\end{array}$ & $\begin{array}{l}\text { - Higher general cognitive } \\
\text { abilities } \\
\text { - Grapheme-color } \\
\text { synesthesia: diminished } \\
\text { motion coherence }\end{array}$ & $\begin{array}{l}\text { When reported in co- } \\
\text { occurrence with autism: } \\
\text { - Enhanced performance for } \\
\text { the block design and } \\
\text { embedded figures tests } \\
\text { - Diminished performance for } \\
\text { tasks involving theory of } \\
\text { mind, executive functions }\end{array}$ \\
\hline
\end{tabular}




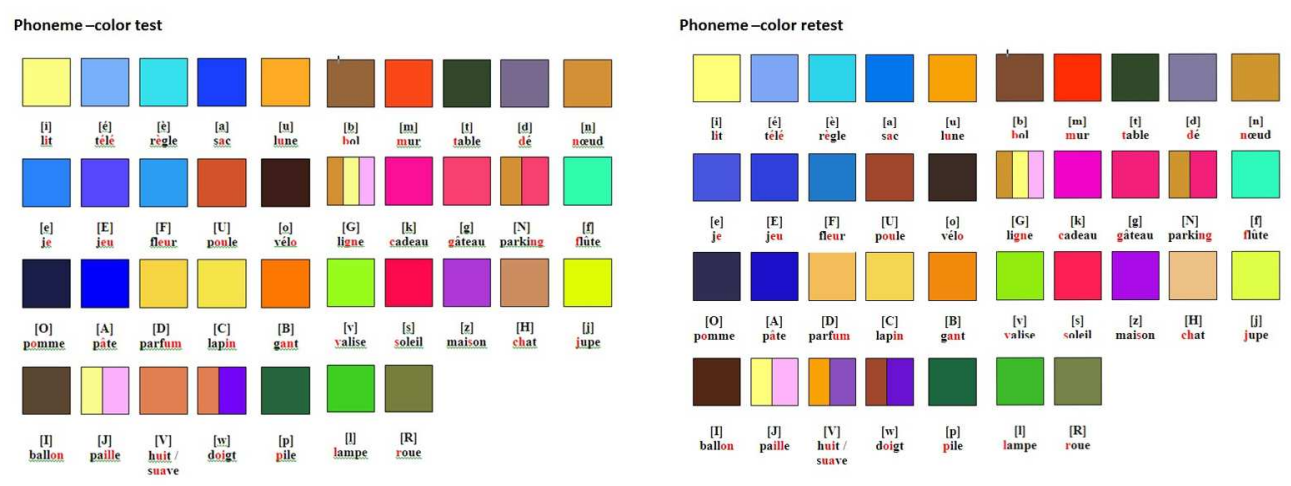

Figure 1. VA's phoneme-color associations $152 \times 57 \mathrm{~mm}(300 \times 300 \mathrm{DPI})$ 